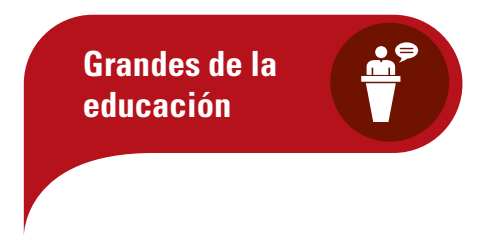

\title{
Anton Makarenko (1888-1939)
}

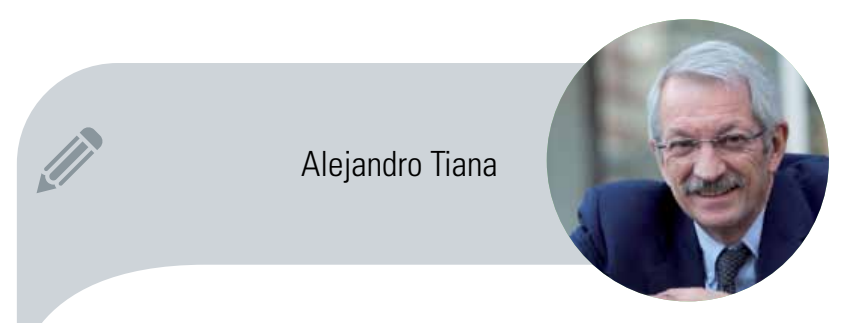

Departamento de Historia de la Educación y Educación Comparada Rector de la UNED atiana@edu.uned.es

Tras la revolución soviética de 1917, la reconstrucción del sistema educativo ruso se hizo perentoria. Por una parte, el aparato escolar había quedado prácticamente desmantelado como consecuencia de la guerra civil. Por otra, los bolcheviques estaban convencidos de que el éxito final de la revolución iba ligado a la construcción de un nuevo tipo de persona y de sociedad, lo que implicaba revisar la educación que deberían recibir los nuevos ciudadanos soviéticos. Para realizar esa tarea se creó el Comisariado del Pueblo para la Educación (conocido como Narkompros), a cuyo frente se situaron Anatoli Lunacharski y su mujer, Nadeshda (Nadia) Krupskaia. El Comisariado desarrolló una importante labor de reorganización educativa durante los años veinte con dos objetivos centrales: eliminar el alto analfabetismo existente y construir una red escolar que permitiese hacer efectiva la escolarización universal.

En una primera etapa y dada la urgencia de la tarea, se buscó fuera de las fronteras rusas la inspiración para reorganizar el sistema educativo. El proyecto revolucionario de construir el nuevo modelo escolar, la denominada Escuela Única del Trabajo, se basó en buena medida en la experiencia y las propuestas pedagógicas de la Escuela Nueva y del movimiento progresista norteamericano, en el que John Dewey ocupó un lugar muy destacado.

Tras una primera década de experimentación pedagógica, comenzó a manifestarse una reacción de rechazo a esas influencias foráneas, que condujo a una revisión del sistema adoptado y a su sustitución paulatina por un modelo escolar más tradicional. Y nadie como Anton Makarenko encarnaría ese nuevo modelo escolar. Si bien otros educadores, como Stanislav Shatsky, habían llevado a cabo experiencias pedagógicas destacables, ninguno de ellos supo aunar la intuición, la firme convicción comunista y el empuje de Makarenko. Esa suma de características personales determinaría su gran influencia sobre la educación soviética, especialmente apreciable durante el periodo estalinista, pero detectable incluso mucho tiempo después.

\section{La vida de un educador}

Anton Semionovich Makarenko nació en Belopole, en el nordeste de Ucrania, en 1888. Cuando tenía doce años, su familia se trasladó a Kremenchug, donde continuó sus estudios. Tras finalizar el instituto, realizó un curso de preparación para maestros de párvulos, de un año de duración, terminado el cual comenzó a trabajar en la escuela de la empresa ferroviaria en la que trabajaba su padre. Ahí comenzó su carrera pedagógica, en la que fue haciéndose cargo de diversas escuelas primarias antes de completar sus estudios en el Instituto Pedagógico de Poltava. A partir de entonces extendería su ámbito de trabajo a la educación secundaria y a la inspección educativa. Al mismo tiempo, entró en los círculos revolucionarios bolcheviques, en los que desarroIlaría una intensa vida política.

Tras la Revolución de Octubre comenzaría su etapa pedagógica más fructífera y conocida. En 1920 se hizo cargo de la de dirección de la colonia Gorki, uno de los centros de acogida y readaptación de los numerosos niños y jóvenes abandonados y delincuentes que había producido la guerra, a cuyo frente estaría hasta el año 1928. Esta experiencia, que fue determinante para el desarrollo de sus concepciones pedagógicas, fue recogida en Poema pedagógico, trilogía cuyo primer volumen fue publicado en 1933 y el último en 1935, y que resulta fundamental para conocer, comprender y analizar sus planteamientos acerca de la educación. Escrita a modo de diario de la vida de la colonia, el libro intercala también capítulos con reflexiones pedagógicas y páginas en las que presenta y comenta el proceso de gestación de sus ideas, que sirven para hacer patente los planteamientos educativos de Makarenko. Esta obra se ha convertido en uno de los principales referentes de la pedagogía soviética en la época estalinista.

En 1928 pasó a dirigir la colonia Dzerzhinski, una institución semejante a la anterior, en la que permaneció hasta 1935. Basándose en esta experiencia escribe un segundo libro, Banderas en las torres, publicado en 1938. En esta segunda obra adopta un estilo novelado para, con la excusa de exponer la vida en la colonia, presentar nuevamente sus principios pedagógicos.

En el año 1935 recibió el encargo de propagar sus ideas sobre la educación por las repúblicas soviéticas, con el objetivo de que sirviesen de ejemplo a los nuevos educadores soviéticos. Comenzó así una etapa de conferenciante, en la que además publicó sus dos obras citadas. Poco después moría en Moscú en 1939, condecorado con la Orden de la Bandera Roja del Trabajo y encumbrado como un ejemplo viviente de la pedagogía soviética.

\section{Pensamiento educativo}

Makarenko fue un educador práctico, más que un teórico de la educación. A lo largo de sus dos obras principales esboza su concepción pedagógica, aunque sin carácter sistemático. Con un estilo literario característico, va hilando en ellas la descripción de los acontecimientos registrados en las colonias que dirigió junto con reflexiones teóricas y con la reconstrucción de los procesos que le 


\section{La organización de los destacamentos en la colonia Gorki}

En este texto se describen las características fundamentales de una de las piezas centrales de la obra pedagógica de Makarenko en la colonia Gorki: los destacamentos.

"La palabra "destacamento" era un término de la época revolucionaria, de aquel tiempo en que las olas revolucionarias no se habían formado aún en esbeltas columnas de regimientos y de divisiones. [...] Nuestros colonos se sentían atraídos más que nada por el romanticismo guerrillero-militar de la lucha revolucionaria. [...] No quería impedir este juego semiconsciente de los instintos revolucionarios de nuestros colonos. Los escritorzuelos pedagógicos que condenaron tan severamente nuestros destacamentos y nuestros juegos militares no podían comprender simplemente de qué se trataba.

El desarrollo de los destacamentos se llevó a cabo con extraordinaria rapidez. [...] Los destacamentos menos densos por el número de sus componentes tendían a distribuir a los colonos por los talleres. [...] Al principio carecíamos de constitución alguna. Yo era quien designaba a los jefes; pero en la primavera empecé a convocar cada vez con mayor frecuencia reuniones de jefes, que los muchachos designaron pronto con un nombre nuevo y hermoso: "Soviet de jefes". [...] En el Soviet de jefes, la elección de cada nuevo jefe iba siempre acompañada de una discusión muy minuciosa. En virtud del sistema de cooptación, disponíamos siempre de jefes magníficos y, al mismo tiempo, de un Soviet que, como un todo único, jamás interrumpió su actividad ni presentó su dimisión.

Norma muy importante, conservada hasta hoy, fue la prohibición absoluta de que el jefe gozase del menor privilegio; jamás obtenía ningún suplemento ni se libraba del trabajo.

En la primavera del año 23 nos enfrentamos con una importante complicación en el sistema de los destacamentos. Esta innovación [la constitución del destacamento mixto] fue la más importante realizada por nuestra colectividad durante los trece años de su existencia. Solo ella permitió a nuestros destacamentos fundirse en una colectividad auténtica y vigorosa, dentro de la que existían diversidad de trabajos y de organización, democracia de la asamblea general, dependencia y sometimiento del camarada al camarada, pero en la cual no se formó ninguna aristocracia, ninguna casta de jefes [...].

El destacamento mixto era un destacamento provisional, constituido todo lo más para una semana, con una misión breve y concreta: escardar la patata en un campo determinado, labrar tal o cual sector, limpiar las semillas, sacar el estiércol, sembrar, etc.

Según era el trabajo, así era el número de colonos que se exigía. Algunos destacamentos mixtos necesitaban dos miembros; otros cinco, ocho, veinte. [...] era un destacamento exclusivamente de trabajo. Tan pronto como concluía su faena, los muchachos volvían a la colonia y el destacamento dejaba de existir.

Cada colono conocía su destacamento permanente, que tenía su jefe también permanente, su lugar determinado en los talleres, su puesto en el dormitorio y en el comedor. El destacamento permanente era la colectividad primaria de los colonos, y su jefe tenía que ser obligatoriamente miembro del Soviet de jefes. Pero, cuando empezaba la primavera y, sobre todo, a medida que iba acercándose el verano, el colono entraba cada vez con mayor frecuencia en esos destacamentos mixtos de trabajo que le tenían atareado una semana en una u otra tarea [...]. El Soviet de jefes designaba a los jefes de los destacamentos mixtos semanales y, después de ello, cada jefe pasaba a formar parte de algún nuevo destacamento mixto ya no como jefe, sino como miembro de filas. [...] Gracias a semejante sistema, la mayoría de los colonos participaban no solo en el trabajo diario, sino también en las funciones de organización. Esto era muy importante: ni más ni menos, lo que hacía falta para la educación comunista. [...].

Esto creaba una cadena muy compleja de dependencia dentro de la colonia y, en tal cadena, era imposible que se destacase y se alzara sobre la colectividad un colono aislado".

Anton Makarenko: Poema pedagógico, Buenos Aires, Editorial Futuro, 1954, vol. 1: El camino hacia la vida, pp. 216-221

Ilevaron a elaborar sus ideas acerca de la educación. El resultado no es un tratado pedagógico, pero sí una obra que deja traslucir claramente sus fundamentos, concepciones y soportes ideológicos.

La idea central de toda su obra consiste en la creación de una sociedad colectiva. Para Makarenko, el objetivo de la educación consiste en formar a los ciudadanos que requiere la nueva sociedad comunista, una nueva sociedad que tiene carácter necesariamente colectivo. Tal es el énfasis que pone en la colectividad, que llega a considerar que debe primar sobre la individualidad. Su propósito es el de lograr una síntesis adecuada de ambas realidades, pero en caso de conflicto lo colectivo debe primar sobre lo individual.

Con ese ánimo recoge en sus colonias a un conjunto de jóvenes delincuentes o predelincuentes, además de huérfanos y niños abandonados, y desarrolla con ellos una interesante labor educativa. La narración de ambas experiencias demuestra que la mayor parte de sus energías se dedicaron a la construcción de una colectividad fuerte y disciplinada. Como él mismo afirma:

"En una colectividad como la nuestra la falta de claridad en las rutas individuales no podía originar la crisis. Las rutas individuales siempre son confusas. ¿Y qué significa un camino individual claro? Es la renuncia a la colectividad, es un espíritu pequeño-burgués concentrado; preocuparse, desde la más tierna edad de algo tan fastidioso como es el futuro pedazo de pan, esa misma tan alabada calificación" (Poema pedagógico, Buenos Aires, Editorial Futuro, 1954, vol. 2: La vida ha comenzado, p. 207).

El énfasis en la vida colectiva se traduce en varios aspectos de la vida cotidiana. Por una parte, la colonia se organiza a partir de pequeños destacamentos de diez a quince personas, que reciben responsabilidades concretas, de las que deben responder solidariamente. Cada individuo es, ante todo, miembro de un 
En su obra puede apreciarse

claramente que son constantes

\author{
las actuaciones encaminadas a la \\ construcción de un sentimiento moral \\ en sus colonos.
}

grupo. Por otra, la colectividad, sea el destacamento, la colonia 0 la propia Unión Soviética, se convierte en referente ineludible de la actuación de los individuos. Los intereses del colectivo deben estar por encima de los personales. Las faltas de responsabilidad o de disciplina son reprendidas por cuanto suponen situar los deseos individuales por delante de las necesidades colectivas..

Desde ese punto de vista, Makarenko critica duramente las pedagogías que sitúan en el centro del proceso educativo los intereses personales. No debe, pues, extrañar que rechazase tajantemente el experimentalismo pedagógico de la primera década revolucionaria. Hasta el inicio del periodo estalinista, su enfrentamiento con las autoridades educativas fue más o menos constante. A partir de ese momento fue considerado un educador ejemplar y recibió un apoyo decidido. La nueva orientación de la política educativa estaba más de acuerdo con sus ideas, por lo que no dudó en implicarse en tareas propagandísticas.

El énfasis en la dimensión colectiva de la educación va íntimamente ligado en Makarenko a la necesidad de llevar a cabo una educación moral. Está convencido de que el nuevo trabajador soviético debe estar imbuido de una profunda moralidad. Lógicamente, se trata de una moral laica, carente de cualquier connotación religiosa, cuyos rasgos fundamentales serían el sentido de responsabilidad, la disciplina, el trabajo y la cooperación. “Nuestra disciplina será severa, la necesitamos porque lo que tenemos que hacer es mucho y difícil. Y lo haremos mal si no tenemos una buena disciplina", dice a los miembros de la colonia Gorki (Poema pedagógico, Buenos Aires, Editorial Futuro, 1954, vol. 3: Vida colectiva, p. 124).

En su obra puede apreciarse claramente que son constantes las actuaciones encaminadas a la construcción de un sentimiento moral en sus colonos. Sus procedimientos de modificación de conducta están fundamentalmente basados en principios psicológicos conductistas, aunque teñidos de una mitología comunista: "nuestra vida debía ser justa como la vida de los verdaderos proletarios [...] debíamos salir de la colonia siendo auténticos komsomoles, para poder también después construir y fortalecer el estado proletario" (Poema pedagógico, Buenos Aires, Editorial Futuro, 1954, vol. 3: Vida colectiva, p. 124).

Fiel a las ideas marxistas, Makarenko combina el trabajo productivo y la educación. Pero, sin embargo, frente a la concepción marxista de la educación politécnica, considera que ambas prácticas deben estar separadas. Dadas las circunstancias que vivieron y la precariedad económica en que debieron desenvolverse, los colonos desarrollaron un trabajo productivo como medio de supervivencia. Pero Makarenko no creía que ese trabajo debiese estar integrado en la tarea escolar, que tenía sus características propias. El trabajo fue considerado uno de los aspectos centrales de la vida de la colectividad, puesto que servía al tiempo para subvenir a sus necesidades y para construir las personalidades de los alumnos. Pero ello no interfería con la importancia también concedida a la instrucción escolar, entendida de un modo bastante tradicional.

Dada la visión optimista que tenía de la naturaleza humana, esencialmente mejorable, y su preocupación por armonizar la educación individual y la vida colectiva, Makarenko se convirtió en un modelo a seguir para los educadores soviéticos del periodo estalinista e incluso en épocas posteriores. Aunque sus concepciones pedagógicas, tributarias de su tiempo, fuesen perdiendo vigencia, su visión utópica de la sociedad revolucionaria ha continuado inspirando a muchos pedagogos hasta épocas recientes•

\section{() Biblografí comentaon}

Las dos obras principales de Makarenko son:

Poema pedagógico: Trilogía compuesta por tres libros: El camino hacia la vida, La vida ha comenzado y Vida colectiva. Publicado originalmente en ruso en 1935. Editado en español en varias ediciones, entre las que cabe destacar las diversas que hizo la Editorial Progreso (Moscú), así como las de Editorial Futuro (Buenos Aires, 1954), Editorial Planeta (Barcelona, 1967 y sucesivas) y Ediciones Akal (1996).

Banderas en las torres: Publicado originalmente en ruso en 1938. Editado en español en varias ediciones, entre las que cabe destacar las diversas que hizo la Editorial Progreso (Moscú), así como la de Editorial Planeta (Barcelona, 1977).

Además de estas ediciones, ambas obras se pueden encontrar y descargar en formato PDF en diversas páginas web, fácilmente localizables mediante cualquier buscador.

Gómez R. de Castro, F.; Tiana Ferrer, A.; Vico Monteoliva, M.; MorgensTERN, S. y ABELLÁN, J. (1991). Socialismo y sistemas educativos, Madrid: UNED.

Kumarin, V. (1975). Antón Makarenko: su vida y labor pedagógica. Moscú: Editorial Progreso.

KumARIN, V. (1977): A. Makarenko: la colectividad y la educación de la personalidad. Moscú: Editorial Progreso.

TRILLA, J., coord. (2009): El legado pedagógico del siglo XX para la escuela del siglo XXI. Barcelona: Grao. 